\title{
Biomechanical Comparison of Lag Screw and Non- spiral Blade Fixation of a Novel Femoral Trochanteric Nail in an Osteoporotic Bone Model
}

Yoshifumi Fuse ( $\square$ yoshifumi1990.aoc@gmail.com )

Saka Midorii Hospital

\section{Yukichi Zenke}

University of Occupational and Environmental Health

\section{Nobukazu Okimoto}

Okimoto Clinic

\section{Toru Yoshioka}

Shimura Hospital

\section{Yoshiaki Yamanaka}

University of Occupational and Environmental Health

\section{Makoto Kawasaki}

University of Occupational and Environmental Health

\section{Hiroshi Terayama}

Saka Midorii Hospital

\section{Akinori Sakai}

University of Occupational and Environmental Health

\section{Research Article}

Keywords: biomechanical test, femoral trochanteric fracture, non-spiral blade, severe osteoporosis bone model, short femoral nail

Posted Date: September 20th, 2021

DOl: https://doi.org/10.21203/rs.3.rs-888733/v1

License: (c) (i) This work is licensed under a Creative Commons Attribution 4.0 International License. Read Full License

Version of Record: A version of this preprint was published at Scientific Reports on January 17th, 2022. See the published version at https://doi.org/10.1038/s41598-022-04844-5. 


\section{Abstract}

\section{Purpose}

There is no consensus regarding the advantages of the lag screw type over the blade type for treating femoral trochanteric fractures. We aimed to investigate whether non-spiral blade (Conventional-Blade, Fid-Blade) nails provide better biomechanical fixation than lag screws in a severe osteoporotic bone model.

\section{Methods}

Different severities of osteoporotic cancellous bone were modelled using polyurethane foam blocks of three densities $\left(0.24,0.16\right.$, and $\left.0.08 \mathrm{~g} / \mathrm{cm}^{3}\right)$. Three torsional tests were performed using each component for each bone density and the maximum torque was recorded, and the energy required to achieve $30^{\circ}$ rotation was calculated. Using a push-in test, the maximum force was recorded, and the energy required to achieve 4-mm displacement was calculated.

Results

For $0.08-\mathrm{g} / \mathrm{cm}^{3}$ density, the peak torques to achieve $30^{\circ}$ rotation, energy required to achieve $30^{\circ}$ rotation, peak force to achieve 4-mm displacement, and energy required to achieve 4-mm displacement were significantly greater for Conventional-Blade and Fid-Blade than for Lag Screw.

\section{Conclusions}

Conventional-Blade and Fid-Blade nails exhibited significantly higher values than Lag Screw under any test condition. The blade-type nail component may have a better fixation capability than the lag screw type in a severe osteoporotic bone model.

\section{Introduction}

Hip fractures among older individuals are major fragility fractures, and early treatment and ambulation are necessary. Femoral trochanteric fractures are more closely associated with a low bone mass than femoral neck fractures, and occur more frequently in older individuals [1]. In older patients, early ambulation without weight-bearing is almost impossible. Therefore, stable fixation of the femoral trochanteric fracture is crucial. Intramedullary nailing is the gold standard for treating unstable femoral trochanteric fractures, with good efficacy and outcomes [2,3]. However, the osteoporosis severity influences cutting out of the nail after femoral intramedullary nailing [4]; consequently, the number of cases of femoral trochanteric fractures, where stable fixation using conventional methods is difficult, may increase for several decades.

Surgeons can choose from between two types of intramedullary nails, namely, the lag screw and blade types, for femoral head fixation in femoral trochanteric fracture treatment. The blade type was developed 
to increase the holding capability of the implant in the femoral head and to lower the cut-out rate [5], but there is no clear consensus regarding the advantages of the lag screw type over the blade type. In addition, the conventional helical blade is inserted using a rotational movement and this rotational movement can cause rotational dislocation of the head, unlike the lag screw, which allows fine rotational adjustment. On the other hand, the non-spiral blade may improve cancellous bone compaction and provide better holding capability, even in the osteoporotic femoral head, by driving the blade into the femoral head without pre-reaming and rotating. However, the biomechanical properties of the non-spiral blade remain unclear.

Accordingly, we aimed to verify whether the fixation capability of the non-spiral blade type is better than that of the lag screw type in a bone model of severe osteoporosis. To this end, we performed biomechanical tests by using synthetic bone models with different densities and verified the efficacy of the non-spiral blade component.

\section{Methods}

We used three components of the Magnum nail (Robert Reid Inc., Tokyo, Japan), which is a nail-type device for improving rotational fixation in severe osteoporosis; this nail can utilise both a lag screw (termed Lag Screw) and blade components in various sizes for femoral head fixation, and the surgeon can choose from among the three components during the surgical procedure [6]. Two blade-style components, termed Blade (Conventional-Blade) and Fid Blade (Fid-Blade), exhibiting a non-spiral shape, are available (Fig. 1). Conventional-Blade has a convex and concave shape, with several longitudinal grooves that prevent it from backing out, while Fid-Blade has large face shapes on the lateral surfaces that enhance rotational resistance. Moreover, Fid-Blade has fewer longitudinal grooves; hence, the nail can be easily pulled out in younger patients.

Polyurethane foam blocks (Sawbones, Vashon Island, WA, USA) were used as a bone substitute material to simulate the cancellous bone in the femoral head. These blocks are $40 \mathrm{~mm}$ in length and width and 50 $\mathrm{mm}$ deep. Blocks of three different densities were used $\left(0.24,0.16\right.$, and $\left.0.08 \mathrm{~g} / \mathrm{cm}^{3}\right): 0.24 \mathrm{~g} / \mathrm{cm}^{3}$ was used to describe a normal bone mineral density, and the other two densities were used to describe the properties in the range of osteoporotic bone $\left(0.16 \mathrm{~g} / \mathrm{cm}^{3}\right.$ for bone with mild osteoporosis and $0.08 \mathrm{~g} / \mathrm{cm}^{3}$ for bone with severe osteoporosis) [7]. Three blocks of each density were prepared for the Lag screw, Conventional-Blade, and Fid-Blade type nails each. To evaluate the fixation capability of the implants, torsional and push-in tests were carried out.

Figure $2 \mathrm{a}$ and $\mathrm{b}$ illustrate the specimens and test setup of the torsional test, respectively, used to measure the rotational resistance of each component. The torsional test was performed three times with each of the three components and each of the three bone densities. Each component was inserted to a depth of $40 \mathrm{~mm}$ (assuming a depth of $10 \mathrm{~mm}$ from the subchondral bone) in advance (Fig. 2a). The tests were performed on a Shimadzu Torsional Testing machine (Shimadzu Corporation, Kyoto, Japan; Fig. 2b) at $24^{\circ} \mathrm{C}$. The components were rotated counter-clockwise with a constant angular velocity of $1 / 60 \mathrm{~s}^{-1}$ while 
the torque was being measured. The implant was only loaded with torque around the axis of the component. Individual torque-angle curves and the maximum torque as rotational resistance were recorded until $180^{\circ}$ of component rotation for each test. The resistance of the torsional test was calculated as the energy required for each implant to achieve rotation of $30^{\circ}$, which corresponded to a linear displacement of $10 \mathrm{~mm}$. The energy values were determined by calculating the area under the torque-angle (in radian) curves.

Figure $2 \mathrm{c}$ and $\mathrm{d}$ illustrate the specimens and test setup of the push-in test, respectively, to measure resistance during the insertion. The push-in test was conducted three times for each of the three components for each of the three bone densities. Tests were performed on an Autograph Tensile Testing machine (AG-X $5.0 \mathrm{kN}$, Shimadzu Corp, Kyoto, Japan; Fig. 2d) at $24^{\circ} \mathrm{C}$. All components were inserted with a constant angular velocity of $20 \mathrm{~mm} / \mathrm{min}$ while the force was being measured. In this test, all components were inserted over a 3.2-mm guide pin to a depth of $40 \mathrm{~mm}$ in advance (Fig. 2a); then, individual force-displacement curves and the maximum force were recorded until the depth of $44 \mathrm{~mm}$ was reached for each test. The resistance encountered in the push-in test was calculated as the energy required for each implant to achieve displacement of $4 \mathrm{~mm}$. The energy values were determined by calculating the area under the force-displacement curves.

Statistical analysis was performed by using a $t$-test in the statistical software JMP ver. 12.2.0 (SAS Institute Inc., Tokyo, Japan). P-values were calculated using one-way analysis of variance with Tukey's HSD test, and $P$-values $<0.05$ were considered significant.

\section{Results}

The peak torques and energy to achieve $30^{\circ}$ rotation in the torsion test are shown in Fig. $3 a$ and $b$, respectively. The lower the bone mineral density, the lower the peak torque and the energy value. At a density of $0.08 \mathrm{~g} / \mathrm{cm}^{3}$, the peak torques to achieve $30^{\circ}$ rotation were significantly greater for Conventional-Blade $(1.38 \pm 0.07 \mathrm{Nm})$ and Fid-Blade $(1.28 \pm 0.04 \mathrm{Nm})$ than for Lag Screw $(0.33 \pm 0.07 \mathrm{~N} \mathrm{~m}$; $P<0.01, P<0.01)$, with no significant differences between Conventional-Blade and Fid-Blade. The energy required to achieve $30^{\circ}$ rotation was also significantly greater for Conventional-Blade $(0.62 \pm 0.04 \mathrm{~J})$ and Fid-Blade $(0.60 \pm 0.01 \mathrm{~J})$ than for the Lag Screw $(0.13 \pm 0.04 \mathrm{~J} ; P<0.01, P<0.01)$, with no significant difference between Conventional-Blade and Fid-Blade. During the torsion test, both Conventional-Blade and Fid-Blade showed significantly higher values than Lag Screw in all bone density specimens. The mean torque-angle curves of the torsional test are shown in Fig. 3c-e. Conventional-Blade and Fid-Blade achieved a higher peak torque value with little rotation than Lag Screw, and they maintained the high value even after rupture, whereas Lag Screw continued to rotate at low torque values.

Figure $4 \mathrm{a}$ and $\mathrm{b}$ show the highest penetration resistance in the push-in test. The higher the bone mineral density, the higher the peak force and the energy required to overcome this resistance. The peak force to achieve 4-mm displacement was significantly greater for Conventional-Blade $(612.48 \pm 26.25 \mathrm{~N})$ and FidBlade $(397.32 \pm 16.93 \mathrm{~N})$ than for Lag Screw $(252.19 \pm 12.14 \mathrm{~N})$ at a density of $0.08 \mathrm{~g} / \mathrm{cm}^{3}$ (both $P<$ 
0.01). Moreover, the peak force to achieve 4-mm displacement was significantly greater for ConventionalBlade than for Fid-Blade $(P<0.01)$. The energy to achieve 4-mm displacement was significantly greater for Conventional-Blade $(1.49 \pm 0.2 \mathrm{~J})$ and Fid-Blade $(1.23 \pm 0.00 \mathrm{~J})$ than for Lag Screw $(0.83 \pm 0.04 \mathrm{~J} ; P<$ $0.01, P<0.05$, respectively), with no significant difference between Conventional-Blade and Fid-Blade.

Thus, for all bone mineral density mimics, the three components ranked in descending order in terms of both peak force and energy to achieve 4-mm displacement: Conventional-Blade > Fid-Blade > Lag Screw. The mean force-displacement curves for the push-in test are shown in Fig. 4c-e, and those for the pushin test for a density of $0.08 \mathrm{~g} / \mathrm{cm}^{3}$ in Fig. 5 . The resistance value of Conventional-Blade and Fid-Blade gradually increased with insertion, whereas that of Lag Screw decreased after reaching the highest insertion resistance value.

\section{Discussion}

This study compared the biomechanical properties of both blade types and lag screw components of the Magnum nail in osteoporotic bone models. Conventional-Blade and Fid-Blade showed significantly higher values than Lag Screw under any of the conditions used in our study. Conventional-Blade and Fid-Blade were three to four times more resistant to rotation than Lag Screw at all bone densities (Fig. 3). Moreover, the energy required for the implant to displace by $4 \mathrm{~mm}$ was the greatest for Conventional-Blade, followed by Fid-Blade, and the least for Lag Screw under all conditions (Fig. 4). Additionally, as the insertion progressed, the fixation capability of the blade type increased, while that of the lag screw type decreased accordingly (Fig. 5).

Regarding the rotation resistance, the peak torque of blade screws at a fracture was $89 \%$ higher than that of lag screws, according to the dynamic hip screw (DHS) test by O'Neill et al. [8]. In the present study, the energies required by Conventional-Blade and Fid-Blade were 1.8 and 1.48 times greater than those required by Lag Screw in a severe osteoporosis model, respectively, and the force of the blade type increased as the insertion progressed. These results suggest that unlike the lag screw type, the two types of blades can be inserted without prior reaming and that the bone around the implant was compacted by compressing the cancellous bone during insertion $[9,10]$. This suggests that Conventional-Blade and FidBlade have higher stability within the femoral head than Lag Screw, and the blade type contributes to decreased cut-out risk, particularly in severely osteoporotic bone.

The principles of fracture treatment include reduction and stable fixation. The importance of reduction in the treatment of trochanteric fractures of the femur, particularly unstable fractures, has been extensively reported in recent years [11-13]. Fang et al. [11] compared 197 cases treated with DHS blade fixation and 242 cases treated with DHS fixation and reported that reduction procedures are more important than implant selection [14]. However, in cases of femoral trochanteric fracture with severe osteoporosis, bony support may be insufficient after reduction, which can cause excessive sliding and rotation of the femoral head, leading to cut-out [15]. The helical blade, which is generally used at present, is useful for stable fixation; however, the reduction position may be rotationally displaced because the helical blade is 
inserted using a rotational movement. Hence, we believe that implant selection may be as important as reduction in the treatment of femoral trochanteric fractures with severe osteoporosis. The Magnum nail (Robert Reid Inc., Tokyo, Japan) is a nail-type device for improving fixation in patients with severe osteoporosis.

There are three major differences between Magnum nails and traditional implants. First, the blades of the Magnum nail have a non-spiral shape that helps avoid the rotational force to the femoral head upon its insertion. Second, the system has two types of blades: Blade (Conventional-Blade) and Fid Blade (FidBlade, with fewer longitudinal grooves that facilitate easier nail removal in young people). Finally, the surgeon can choose from among the three components, including two blade-style components and Lag Screw, during surgery.

Our push-in test for severe osteoporosis $\left(0.08-\mathrm{g} / \mathrm{cm}^{3}\right.$ density) showed that Conventional-Blade had a significantly higher resistance force than the other two types (Fig. 4), and the force of the blade type increased, whereas that of the lag screw decreased with progression of the insertion (Fig. 5). The convex and concave-shaped structure of Conventional-Blade was considered to have adequate thickness for insertion without rotational movement and could compress the bone around the blade, thus contributing to the high resistance value. Conventional-Blade was superior to the other two types with respect to insertion and rotation resistance in our study, which may contribute to reducing the cut-out risk when treating femoral trochanteric fractures in patients with severe osteoporosis, the incidence of which will increase further in older patients.

However, this result recommends careful consideration of the difficulty of insertion and removal of the Conventional-Blade, particularly in patients with normal bone mineral density. Figure 6 shows the protrusion of the Conventional-Blade on the surface of the polyurethane foam block following the push-in test. This protrusion may worsen because of excessive intraoperative insertional force and postoperative weight-bearing and may lead to 'cut through', i.e. migration of implants into the pelvis, which is among the complications reported in patients with blade fixation. Therefore, surgeons should be mindful of the risk of iatrogenic fractures, difficulty of insertion, and reduction loss with bone compaction and carefully consider using the Conventional-Blade, particularly in cases with normal bone density. If it is difficult to insert the Conventional-Blade, pre-reaming is required. Further, pre-reaming reduces the fixation force of the blade; thus, we believe that Lag Screw can be safely used in such cases. Additionally, in younger patients with normal bone mineral density, the removal of Lag Screw and Conventional-Blade can be difficult owing to the structure of these devices. In such cases, surgeons can select Fid-Blade, which has large face shapes on the lateral surfaces that enhance rotational resistance and fewer longitudinal grooves that facilitate easier nail removal. In this respect, the Magnum nail is useful, as the surgeon can choose from among three components, with reference to the sensation of drilling in the femoral head.

Thus, our results indicate that a suitable implant for fixation of the femoral head may vary according to the patient's bone density of the patient. We consider that the blade type is better than the lag screw type in severe osteoporotic bone; however, in patients with normal bone mineral density, the blade type 
(especially Conventional-Blade) should still be inserted cautiously. The various options available with the Magnum nail system allow the best implant selection for patients, ranging from young patients to patients with severe osteoporosis, and the Magnum nail is adaptable to variations in fracture types and bone quality. Thus, this system can facilitate stable fixation and should lead to a reduction in postoperative complications.

This study has some limitations. First, it used a bone model instead of a cadaveric bone. Further studies in bone models $<0.08 \mathrm{~g} / \mathrm{cm}^{3}$ are necessary to evaluate the fixation capability of the implants in more severe osteoporotic bone models. Nonetheless, $0.08 \mathrm{~g} / \mathrm{cm}^{3}$ is the lowest density in the variation of Sawbones' polyurethane foam. Our study is important because it compares the fixing forces of non-spiral blades and lag screws using the lowest density polyurethane blocks available. Second, this experiment involved only a static rather than a dynamic test under conditions of an added rotational moment and axial load. Further studies, such as dynamic tests under the condition of combining the rotation moment and axial load, are necessary.

\section{Conclusion}

The findings suggest that the fixation capability of the blade-type Magnum nail component is better than that of the lag screw type in a severe osteoporotic bone model. Thus, the blade-type Magnum nail component may be useful for treating femoral trochanteric fractures in patients with severe osteoporosis.

\section{Declarations}

\section{Acknowledgments}

The tortional test and push-in test were performed at Kobe Steel, Ltd. We would like to thank Editage (www.editage.com) for English language editing.

Authors' contributions: Y.F:: Advisor of Implant Design, Conceptualisation, Data Curation, Investigation, Methodology, Visualisation, Writing-Original Draft. Y.Z.: Investigation, Visualisation, Supervision, WritingReviewing and Editing. N.O.: Advisor of Implant Design, Conceptualisation, Methodology, WritingReviewing and Editing. T.Y.: Advisor of Implant Design, Conceptualisation, Writing-Reviewing and Editing. Y.Y: Writing-Reviewing and Editing. M.K.: Writing-Reviewing and Editing. H. Terayama: Writing-Reviewing and Editing. A.S.: Writing-Reviewing and Editing.

\section{Additional information}

Conflict of interest: The authors declare that they have no relevant financial or non-financial interests to report.

Funding: This work was supported by Robert Reid Inc. 
Neither the authors nor any member of their immediate families received payments or other benefits or a commitment or agreement to provide such benefits from a commercial entity. The study was jointly designed by the primary investigators and sponsor. The sponsor was not involved in the collection, analysis, or interpretation of data; in the writing of the report; and in the decision to submit the article for publication.

Availability of data and materials: Not applicable.

Ethical approval: Approval from the institutional review board was not required because this study did not include any human participants or data.

Informed consent: Not applicable.

\section{References}

1. Mautalen, C. A., Vega, E. M. \& Einhorn, T. A. Are the etiologies of cervical and trochanteric hip fractures different? Bone. 18, 133S-137S. (1996) https://doi.org/10.1016/8756-3282(95)00490-4

2. Haidukewych, G. J. Intertrochanteric fractures: ten tips to improve results. Instr. Course Lect. 59, 503509. (2010)

3. Palm, H. et al. Intramedullary nailing appears to be superior in pertrochanteric hip fractures with a detached greater trochanter: 311 consecutive patients followed for 1 year. Acta Orthop. 82, 166-170. (2011) https://doi.org/10.3109/17453674.2011.566143

4. Lobo-Escolar, A., Joven, E., Iglesias, D. \& Herrera, A. Predictive factors for cutting-out in femoral intramedullary nailing. Injury. 41, 1312-1316. (2010) https://doi.org/10.1016/j.injury.2010.08.009

5. Yaozeng, X., Dechun, G., Huilin, Y., Guangming, Z. \& Xianbin, W. Comparative study of trochanteric fracture treated with the proximal femoral nail anti-rotation and the third generation of gamma nail. Injury. 41, 1234-1238. (2010) https://doi.org/10.1016/j.injury.2010.03.005

6. Fuse, Y. et al. Treatment experience of a new device for trochanteric fractures. Hip Joint. 41, 321-324. (in Japanese) (2015)

7. Patel, P. S., Shepherd, D. E. \& Hukins D. W. The effect of screw insertion angle and thread type on the pullout strength of bone screws in normal and osteoporotic cancellous bone models. Med. Eng. Phys. 32, 822-828. (2010) https://doi.org/10.1016/j.medengphy.2010.05.005

8. O'Neill, F. et al. Dynamic hip screw versus DHS blade: A biomechanical comparison of the fixation achieved by each implant in bone. J. Bone Joint Surg. Br. 93, 616-621. (2011) https://doi.org/10.1302/0301-620X.93B5.25539 
9. Goffin, J. M., Pankaj, P., Simpson, A. H., Seil, R. \& Gerich, T. G. Does bone compaction around the helical blade of a proximal femoral nail anti-rotation (PFNA) decrease the risk of cut-out?: A subject-specific computational study. Bone Joint Res. 2, 79-83. (2013) https://doi.org/10.1302/2046-3758.25.2000150

10. Windolf, M. et al. Quantification of cancellous bone-compaction due to DHS Blade insertion and influence upon cut-out resistance. Clin. Biomech. 24, 53-58. (2009)

https://doi.org/10.1016/j.clinbiomech.2008.09.005

11. Fang, C., Lau, T.W., Wong, T. M., Lee, H. L. \& Leung, F. Sliding hip screw versus sliding helical blade for intertrochanteric fractures: A propensity score-matched case control study. Bone Joint J. 97-B, 398-404. (2015) https://doi.org/10.1302/0301-620X.97B3.34791

12. Ito, J. et al. Prevention of excessive postoperative sliding of the short femoral nail in femoral trochanteric fractures. Arch. Orthop. Trauma Surg. 135, 651-657. (2015) https://doi.org/10.1007/s00402015-2200-3

13. Yoo, J. H., Kim, T. Y., Chang, J. D., Kwak, Y. H. \& Kwon, Y. S. Factors influencing functional outcomes in united intertrochanteric hip fractures: A negative effect of lag screw sliding. Orthopedics. 37, e1101e1107. (2014) https://doi.org/10.3928/01477447-20141124-58

14. Kozono, N. et al. Direct reduction may need to be considered to avoid postoperative subtype $P$ in patients with an unstable trochanteric fracture: A retrospective study using a multivariate analysis. Arch Orthop. Trauma Surg. 134, 1649-1654. (2014) https://doi.org/10.1007/s00402-014-2089-2

15. Chinzei, N. et al. Comparison of the sliding and femoral head rotation among three different femoral head fixation devices for trochanteric fractures. Clin. Orthop. Surg. 7, 291-297. (2015) https://doi.org/10.4055/cios.2015.7.3.291

\section{Figures}




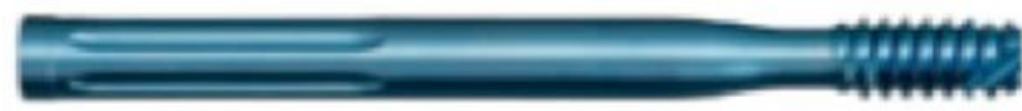

(a)

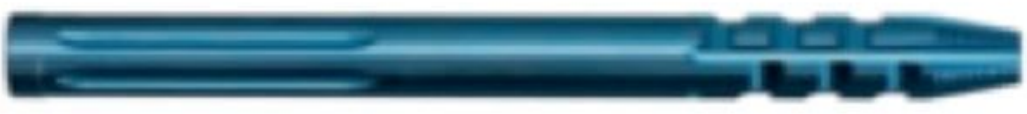

(b)
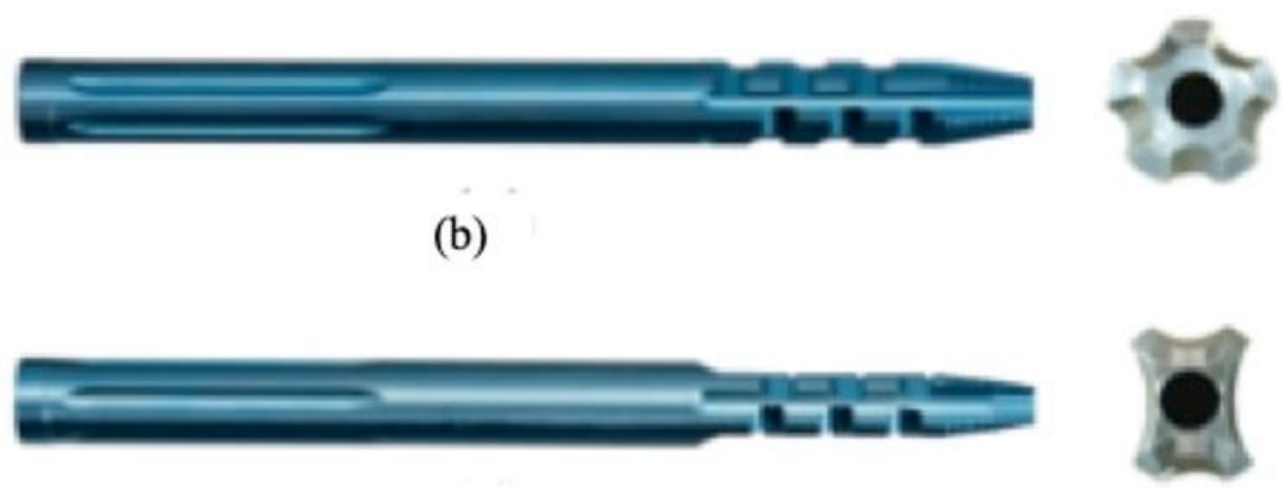

(c)

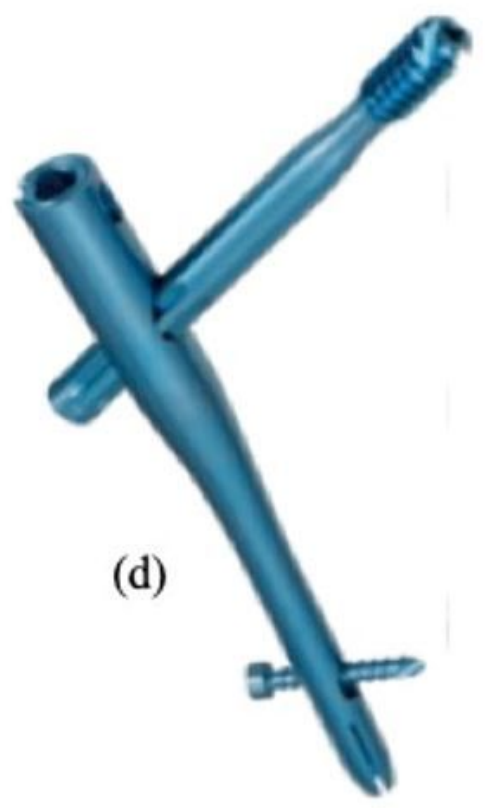

(d)

\section{Figure 1}

(a) Lag Screw component. (b) Conventional-Blade component, showing its cross-sectional shape. (c) FidBlade and its cross-sectional shape (two-face-cut design). Both blades are driven into the femoral head without rotation. (d) Magnum nail 


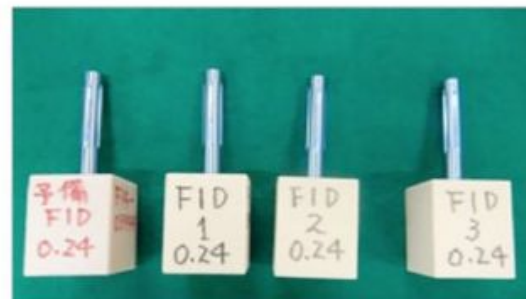

67898123456709012345670956250507

(a)

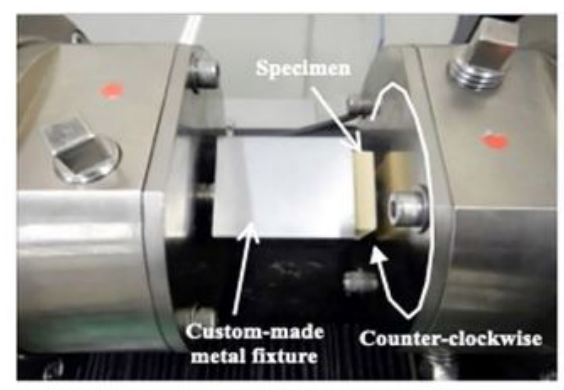

(b)

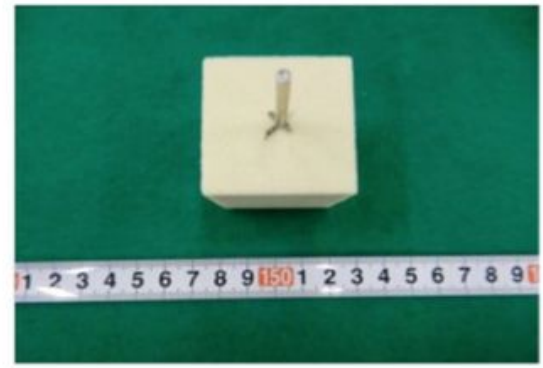

(c)

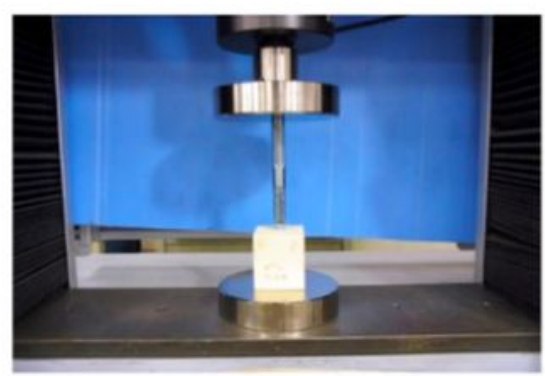

(d)

Figure 2

(a) Specimens of three bone densities: $0.24 \mathrm{~g} / \mathrm{cm} 3,0.16 \mathrm{~g} / \mathrm{cm} 3$, and $0.08 \mathrm{~g} / \mathrm{cm} 3$. (b) Shimadzu Torsional Testing machine. (c) Specimens inserted to a depth of $40 \mathrm{~mm}$ in advance. (d) Autograph Tensile Testing machine 

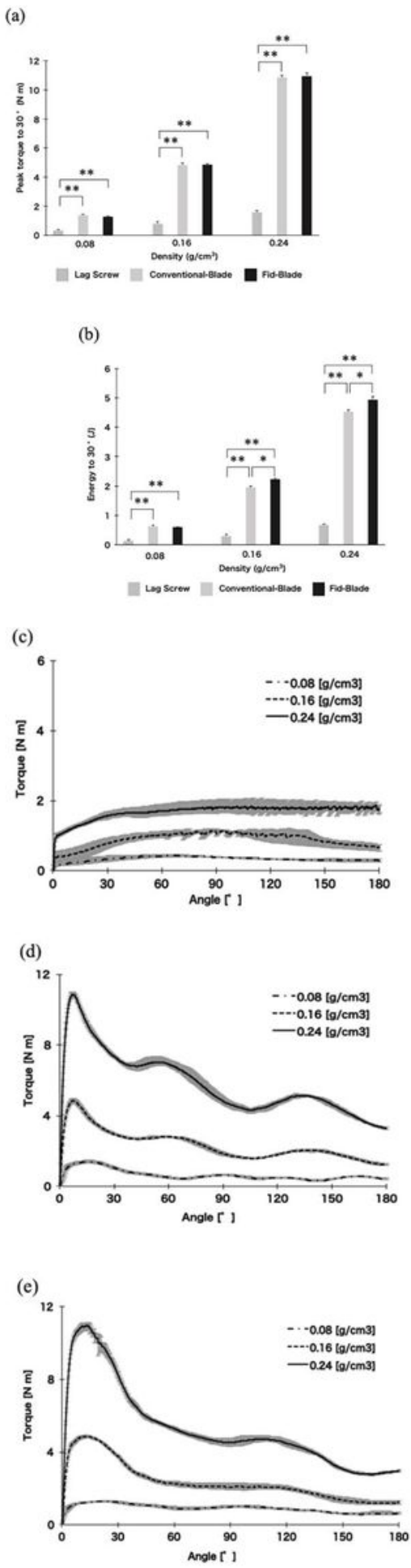

Figure 3

Torsion test (a) Mean peak torque to achieve $30^{\circ}$ rotation. (b) Mean energy to achieve $30^{\circ}$ rotation. ${ }^{\star} P<0.05$. ${ }^{\star \star} \mathrm{P}<0.01$ (c-e) Mean torque-angle curves (c) Lag Screw. (d) Conventional-Blade. (e) Fid-Blade 
(a)

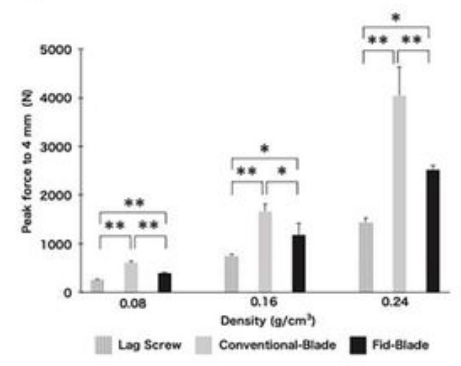

(b)

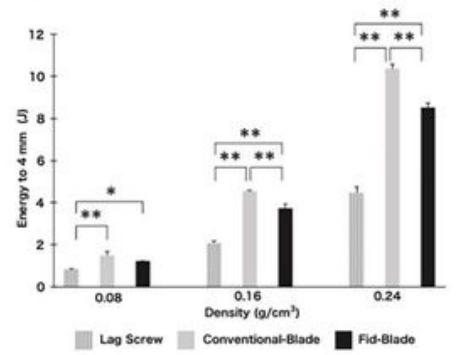

(c)

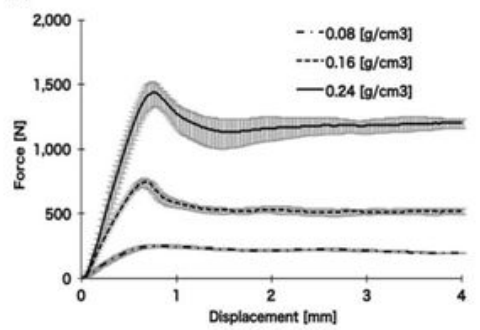

(d)

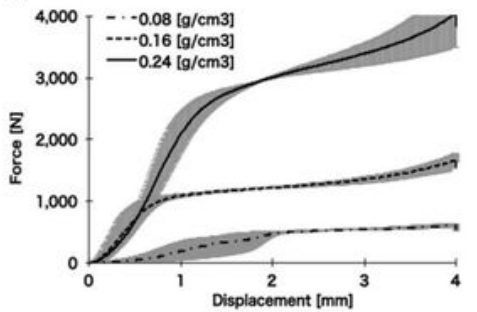

(e)

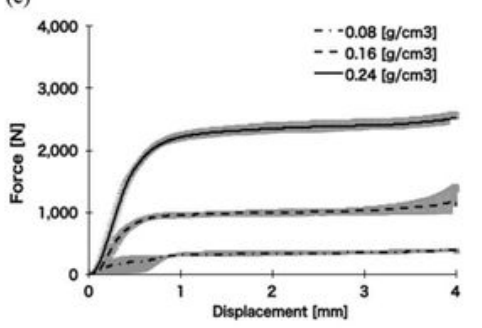

Figure 4

Push-in test (a) Mean peak force to achieve 4-mm displacement. (b) Mean energy force to achieve 4-mm displacement. ${ }^{\star} \mathrm{P}<0.05$. ${ }^{\star *} \mathrm{P}<0.01$ (c-e) Mean force-displacement curves. (c) Lag Screw. (d) ConventionalBlade. (e) Fid-Blade 
(a)

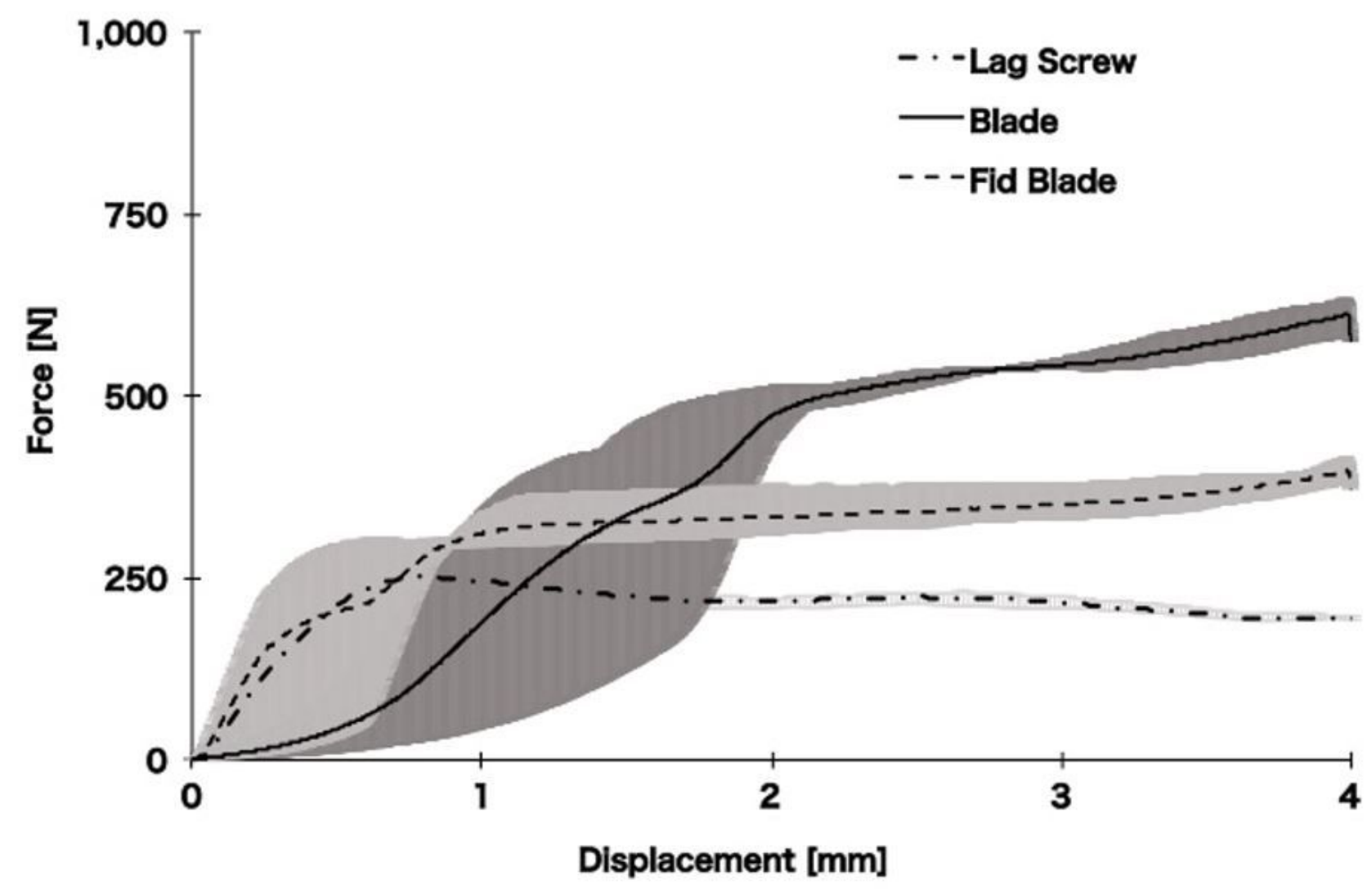

Figure 5

Mean force-displacement curves for the push-in test for a density of $0.08 \mathrm{~g} / \mathrm{cm} 3$. The three components ranked in descending order, by both peak force and energy, to achieve 4-mm displacement: ConventionalBlade $>$ Fid-Blade $>$ Lag Screw. 


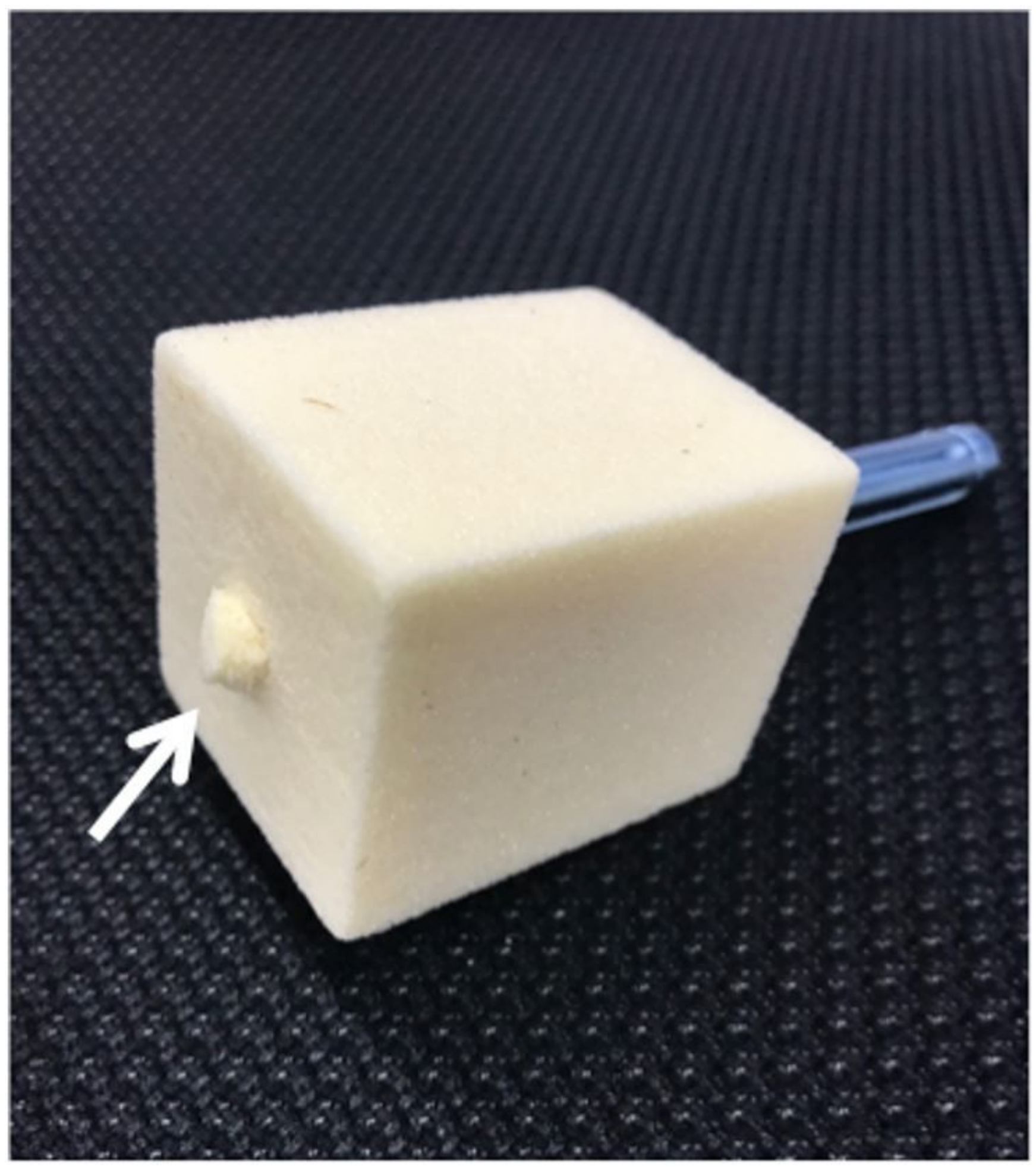

Figure 6

Protrusion of the nail on the surface of the polyurethane foam block following the push-in test (white arrow). 